\section{A) Check for updates}

Cite this: Food Funct., 2020, 11, 7104

\title{
Structural characterization of a homopolysaccharide with hypoglycemic activity from the roots of Pueraria lobata $\uparrow$
}

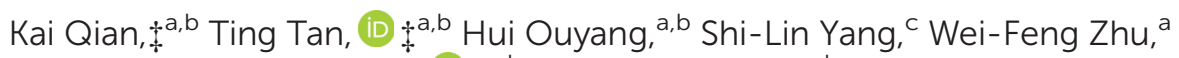 \\ Rong-Hua Liu, ${ }^{a}$ Quan Wen (D)*a,b and Yu-Lin Feng*a,b,c
}

\begin{abstract}
A water-soluble neutral homopolysaccharide (PLP-1) was obtained from the roots of Pueraria lobata by DEAE cellulose and Sephadex G-200 gel chromatography purification. The average molecular weight of PLP-1 was $16.2 \mathrm{kDa}$. Monosaccharide composition analysis showed that PLP-1 was composed of glucose as a glucan. The structure of PLP-1 was characterized on the basis of extensive physical and chemical analysis, which indicated that the backbone of PLP-1 was mainly composed of $\rightarrow 3)-\alpha-D-G l c p(1 \rightarrow$ and $\rightarrow 4)$ - $\beta$-D-Glcp $(1 \rightarrow$ with a molar ratio of $7.0: 1.0$. Moreover, the hypoglycemic activity of PLP-1 was investigated by palmitic acid and high glucose induced insulin resistant HepG2 cells. The results elucidated that PLP-1 could decrease the glucose concentration by up-regulating the expression of PI3K and AKT, and down-regulating the expression of FoxO1, PCK2, and G6Pase in insulin resistant cells. Therefore, PLP-1 could serve as a dietary supplement to ameliorate insulin resistance for diabetic patients.
\end{abstract}

Received 12th May 2020, Accepted 20th July 2020

DOI: $10.1039 /$ dOfo0 $1234 c$ rsc.li/food-function natural edible plant products with low toxicity and hypoglycemic effect are attractive to many researchers. ${ }^{6,7}$

Pueraria lobata (Willd.) Ohwi, belonging to the genus Pueraria of the family Leguminosae, is one of the earliest known and most important edible vine herbs in most parts of China. ${ }^{8}$ Biological studies have indicated that roots of $P$. lobata have potential effects, exhibiting antidiabetic, ${ }^{9}$ antihypertensive, ${ }^{10}$ antioxidative, ${ }^{11}$ antiosteoporosis ${ }^{12}$ and immunoregulatory ${ }^{13}$ activities. Aqueous extract of $P$. lobata has been used by local Chinese people and hospitals in folk medicine for the treatment of diabetes mellitus, or as an ingredient for many Chinese prescriptions for anti-diabetes formulations, ${ }^{14}$ but the active constituents of aqueous extract of $P$. lobata are ambiguous. Interestingly, it has been reported that the crude polysaccharides from roots of $P$. lobata have potential for treatment of T2DM in rats. ${ }^{15}$ However, which kind of homopolysaccharides with particular structures from such crude polysaccharides that exert pharmacological activity is still unclear.

Therefore, the aim of this study was to isolate and purify active hypoglycemic homopolysaccharides from water extract of roots of P. lobata, and to elucidate the structural characteristics. Furthermore, the potential mechanism of action was investigated using insulin resistant HepG2 cells.

\section{Materials and methods}

\subsection{Materials and reagents}

The roots of $P$. lobata were purchased from Zhangshu, Jiangxi province, China. The sample ( $P$. lobata) was identified by 
Professor Fei Ge at School of Pharmacy, Jiangxi University of Traditional Chinese Medicine, Nanchang, China, where a voucher specimen (no. PL-190210-07) is deposited. Palmitic acid, metformin hydrochloride and glucose assay kit were purchased from Solarbio Science \& Technology Co. Ltd (Beijing, China). DEAE-52 cellulose and Sephadex G-200 were purchased from Yuanye Bio-Technology Co. Ltd (Shanghai, China). Dextran standards and monosaccharide standards were purchased from National Institutes for Food and Drug Control. Dimethyl sulfoxide (DMSO) and iodomethane were purchased from Chemical Technology Co. Ltd (Shanghai, China). Sodium hydride and potassium bromide were purchased from Aladdin Reagent Co. Ltd (Shanghai, China). Deuterium oxide $\left(\mathrm{D}_{2} \mathrm{O}\right)$ was purchased from Qiaoyi Biotechnology Co. Ltd (Shanghai, China). Ultrapure water was prepared from a Milli-Q water purification system (Millipore, MA, USA). All other chemicals were of analytical grade. TRIzol was purchased from ThermoFisher Scientific Inc. (Invitrogen, USA). cDNA synthesis kit and TransStart Tip Green qPCR kit were purchased from TransGen Biotechnology Co. Ltd (Beijing, China). $\beta$-Actin, PI3K, GSK-3 $\beta$, FoxO1, PCK2 primary antibody and lgG secondary antibody were purchased from Cell signaling Technology (Boston, USA). AKT and G6Pase primary antibody were obtained from Abcam (Cambridge, UK).

\subsection{Extraction and purification of polysaccharides}

The method of water extraction and alcohol precipitation in our laboratory was used to extract crude polysaccharides. ${ }^{16}$ Briefly, the dried roots of P. lobata (500 g) were crushed into coarse powder and extracted twice with 10 times the amount of deionized water for $3 \mathrm{~h}$ each time by a reflux device. All water extracts were combined and concentrated to about $1.0 \mathrm{~L}$ using a rotavapor vacuum concentrator (EYELA N-1300, Tokyo, Japan), which was then precipitated with anhydrous ethanol $(1: 3, \mathrm{v} / \mathrm{v}, 3 \mathrm{~L})$ at $4{ }^{\circ} \mathrm{C}$ for $12 \mathrm{~h}$, followed by centrifugation at $4000 \mathrm{~g}$ for $10 \mathrm{~min}$ using a centrifuge (Xiang li CTL550, Hunan, China). The precipitate dissolved in $400 \mathrm{~mL}$ of ultrapure water was then centrifuged at $4000 \mathrm{~g}$ for $10 \mathrm{~min}$. All supernatant liquids were collected and concentrated to about $200 \mathrm{~mL}$, which was then lyophilized at $-80{ }^{\circ} \mathrm{C}$ (FD-1C-80, Shanghai, China) to obtain crude polysaccharide PLP (10.2 g). PLP was dissolved in distilled water, then loaded on macroporous resin HP-20 (Mitsubishi, Japan) to remove proteins and pigments, which was eluted with deionized water by decompression filtration. Eluent was concentrated to about $100 \mathrm{~mL}$, followed by centrifugation at $4000 \mathrm{~g}$ for $10 \mathrm{~min}$. All supernatant liquids were eluted by distilled water on DEAE- 52 cellulose column until phenol-sulfuric acid reaction ${ }^{17}$ showed a colorless result. After that, the fraction was further purified by Sephadex G-200 chromatography, ${ }^{18}$ eluted with deionized water at a flow rate of $1.0 \mathrm{~mL} \mathrm{~min}^{-1}$ to obtain PLP-1 $(1.2 \mathrm{~g})$. The homogeneity of PLP-1 was determined by HPGPC-RID methods (Fig. S1†).

\subsection{Structural characterization of PLP-1}

2.3.1. Purity and chemical properties analysis. The purity and molecular weight of PLP-1 were determined by high- performance gel permeation chromatography (HPGPC) with a differential refractive index detector (RID-20A, Shimadzu, Japan) and TSK gel G3000PWXL column $(7.8 \times 300 \mathrm{~mm}$, TOSOH, Japan). ${ }^{19}$ The mobile phase was $0.1 \mathrm{~mol} \mathrm{~L}^{-1}$ sodium nitrate solution at a flow rate of $0.6 \mathrm{~mL} \min ^{-1}$ at $35{ }^{\circ} \mathrm{C}$. A series of dextran (D0, D1, D2, D3, D4, D5, D6 and D7) were chosen as the calibration standards. The retention times were plotted against the logarithms of the average molecular weight of standards, and the relative molecular weight of PLP-1 was calculated according to the standard curve.

The total sugar was determined by the phenol-sulfuric acid method with D-glucose as standard. ${ }^{20}$ The content of protein was measured by the Bradford method with bovine serum albumin as standard. ${ }^{21}$

2.3.2. Monosaccharide composition analysis. GC-MS analysis was carried out according to a reported method. ${ }^{22}$ PLP-1 (3 mg) was hydrolyzed with $2 \mathrm{M}$ trifluoroacetic acid (TFA) $(3 \mathrm{~mL})$ in an oil bath $\left(100{ }^{\circ} \mathrm{C}\right)$ for $6 \mathrm{~h}$ in a sealed tube. The hydrolyzed product and monosaccharide standards were reduced with sodium borohydride $(40 \mathrm{mg})$ at room temperature for $2 \mathrm{~h}$, which were then neutralized with $20 \%$ glacial acetic acid until no bubbles were produced. Finally, the reduced product was acetylated with acetic anhydride $(1.5 \mathrm{~mL})$ and pyridine $(1.5 \mathrm{~mL})$ in an oil bath $\left(100^{\circ} \mathrm{C}\right)$ for $1 \mathrm{~h}$. The alditol acetates were analyzed by GC-MS (Agilent 7890A) equipped with an HP-5MS column $(30.0 \mathrm{~m} \times 0.25 \mathrm{~mm}$, $0.25 \mu \mathrm{m}$, Agilent, USA). Conditions: injection temperature $280{ }^{\circ} \mathrm{C}$, column velocity $1.66 \mathrm{~mL} \mathrm{~min}^{-1}$, column temperature programmed from 140 to $180{ }^{\circ} \mathrm{C}$ at $2{ }^{\circ} \mathrm{C} \mathrm{min}^{-1}$, then increasing to $185{ }^{\circ} \mathrm{C}$ (holding for $3 \mathrm{~min}$ ) at $1{ }^{\circ} \mathrm{C} \mathrm{min}^{-1}$, increasing to $188^{\circ} \mathrm{C}$ (holding for $5 \mathrm{~min}$ ) at $1^{\circ} \mathrm{C} \mathrm{min}^{-1}$, increasing to $192{ }^{\circ} \mathrm{C}$ (holding for $2 \mathrm{~min}$ ) at $1^{\circ} \mathrm{C} \mathrm{min}^{-1}$, increasing to $200{ }^{\circ} \mathrm{C}$ at $2^{\circ} \mathrm{C}$ $\mathrm{min}^{-1}$, and finally to $250{ }^{\circ} \mathrm{C}$ (holding for $4 \mathrm{~min}$ ) at $5^{\circ} \mathrm{C} \mathrm{min}^{-1}$. Nitrogen was used as the carrier gas.

2.3.3. Infrared spectral analysis. $2 \mathrm{mg}$ of PLP-1 sample was ground with $200 \mathrm{mg} \mathrm{KBr}$ powder and then pressed into pellets, and spectra recorded with a Fourier transform infrared spectrometer (EQUINOX 55, Bruker, Germany) in the frequency range of $4000-500 \mathrm{~cm}^{-1} \cdot{ }^{23}$

2.3.4. Methylation and GC-MS analysis. Methylation reactions were carried out 2 times until the absence of the absorption peak corresponding to hydroxyl band (3200-3700 $\left.\mathrm{cm}^{-1}\right)$ in FT-IR spectra according to previously reported methods ${ }^{24}$ with slight modification. Briefly, sodium hydride ( $2 \mathrm{~g}$ ) with oil was treated with anhydrous petroleum ether $(20 \mathrm{~mL})$ by means of shock and static settling. Afterwards, the petroleum ether was dumped. The process was repeated 3 times to obtain oil-free sodium hydride, which was blown until it was powdered by nitrogen. Anhydrous DMSO $(20 \mathrm{~mL})$ was injected and reacted in an oil bath $\left(50^{\circ} \mathrm{C}\right)$ for $6 \mathrm{~h}$. Finally, the reaction solution was filled with nitrogen and stored for further use.

PLP-1 (10 mg) was dissolved in a reaction flask with anhydrous DMSO $(2 \mathrm{~mL})$, and placed on a magnetic agitator with nitrogen protection. Then the reaction solution $(2.5 \mathrm{~mL})$ was injected slowly and reacted at room temperature for $30 \mathrm{~min}$. Afterwards, iodomethane was added to the reaction flask in an 
ice bath for 3 hours. After that, the resulting solution was dialyzed using 3500 Da dialysis membrane (MD 44, Solarbio, China) in flowing water for $48 \mathrm{~h}$ and deionized water for $24 \mathrm{~h}$. The products of complete methylation were hydrolyzed, reduced and acetylated according to the above monosaccharide composition and analyzed by GC-MS. MS analysis conditions: injection temperature was $280^{\circ} \mathrm{C}$, electron energy was $70 \mathrm{eV}$, the ion source temperature was $230^{\circ} \mathrm{C}$, scanning mode was selective ion detection, solvent was removed during $2.5 \mathrm{~min}$.

2.3.5. Nuclear magnetic resonance (NMR) spectroscopy analysis. $20 \mathrm{mg}$ PLP-1 was dissolved in $0.6 \mathrm{~mL} \mathrm{D}_{2} \mathrm{O}$ for NMR analysis. The $1 \mathrm{D}-\mathrm{NMR}\left({ }^{1} \mathrm{H}-\mathrm{NMR},{ }^{13} \mathrm{C}-\mathrm{NMR}\right)$ and $2 \mathrm{D}-\mathrm{NMR}$ (DEPT-135 ${ }^{\circ}$ HSQC, HMBC and ${ }^{1} \mathrm{H}-{ }^{1} \mathrm{H}$ COSY) spectra were recorded with an NMR instrument (600 M, Bruker, Germany) at $25^{\circ} \mathrm{C}$.

2.3.6. Atomic force microscopy (AFM) analysis. Surface topography of PLP-1 was investigated according to a previous report. $^{25}$ Briefly, PLP-1 was fully dissolved in distilled water. The solution was further diluted to $10 \mu \mathrm{g} \mathrm{mL} \mathrm{m}^{-1}$, placed on a freshly cleaved mica plate and dried thoroughly in ambient air. This caused adhesion of molecules to substrate which facilitates scanning of biopolymer by the AFM tip. AFM was conducted in contact mode (NanoScope, Bruker, USA). Twodimensional images were captured with Nanoscope software (Bruker).

\subsection{Assay of hypoglycemic activity in vitro}

2.4.1. Cell cultures. Human HepG2 cell lines were supplied from Chinese Academy of Science (Shanghai, China). Dulbecco's Modified of Eagle's Medium (DMEM) was purchased from Solarbio Science \& Technology Co. Ltd. Fetal bovine serum (FBS) was purchased from ThermoFisher Scientific Inc. (Gibco, USA). HepG2 cells were cultured in DMEM supplemented with $10 \%$ FBS and 1\% penicillin/streptomycin at $37{ }^{\circ} \mathrm{C}$ in a $5 \% \mathrm{CO}_{2}$ humidified environment.

2.4.2. Cytotoxicity assay. HepG2 cells were seeded in 96-well plates $\left(5 \times 10^{3}\right.$ cells per well $)$ and allowed to adhere for $24 \mathrm{~h}$. After that, cells were treated with various concentrations of PLP-1 (1.925 $\mu \mathrm{M}, 3.85 \mu \mathrm{M}, 7.7 \mu \mathrm{M}, 15.4 \mu \mathrm{M}, 30.8 \mu \mathrm{M})$ for $24 \mathrm{~h}$. Cells treated with medium were used as control group. Then, the cell viability was determined by MTT assay. ${ }^{26}$ The absorbance of each well was measured with a multi-function enzyme labeling instrument (Spectra Max i3, Molecular Devices, USA). The absorbance of untreated cells was considered as $100 \%$.

2.4.3. Effect of PLP-1 on glucose metabolism in insulin resistant model HepG2 cells. In order to explore the effect of PLP-1 on glucose metabolism, IR model HepG2 cells were used according to the method of previous reports with slight

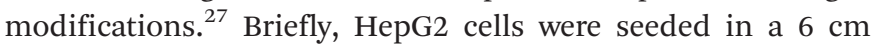
culture dish and allowed to adhere for $24 \mathrm{~h}$. The IR cell models were induced with $0.5 \mathrm{mM}$ palmitic acid (PA) plus $30 \mathrm{mM}$ glucose (Glu) in $2 \%$ serum medium for $8 \mathrm{~h}$. Then, PLP-1 was dissolved in PBS and diluted to the required concentrations $(30.8,15.4$, and $7.7 \mu \mathrm{M})$ with culture medium and incubated with IR cells for 10 h. $2 \mathrm{mM}$ metformin (Met) was used as a positive control and PBS as a blank control. The Glu content was measured with a glucose assay kit according to the instructions. The content of Glu was calculated according to the concentration of protein, and expressed as $\mu \mathrm{mol} \mathrm{mg} \mathrm{m}^{-1}$ protein. $^{28}$

2.4.4. Quantitative real-time polymerase chain reaction (RT-PCR). The mRNA expression levels of PI3K, AKT, GSK-3 $\beta$, FoxO1, PCK2 and G6Pase were determined by the RT-PCR process. ${ }^{29}$ HepG2 cells were seeded and grown to confluence, induced to insulin resistance by PA and Glu for $8 \mathrm{~h}$, then treated with PLP-1 $(30.8 \mu \mathrm{M})$ and $\mathrm{Met}(2 \mathrm{mM})$ respectively. Untreated cells were used as a control group. After incubation for $10 \mathrm{~h}$, total RNA from HepG2 cells was extracted using TRIzol Reagent (Invitrogen) and RNA was reverse transcribed to cDNA using a cDNA synthesis kit (Trans) according to the manufacturer's instructions. RT-PCR analysis was performed using SYBR ${ }^{8}$ Green Reagents on ABI prism 7500 software. Primer pairs (Table S1†) were designed and synthesized by Tsingke Biotechnology Co. Ltd (Beijing, China). The levels of transcripts were normalized using $\beta$-actin as an internal standard. Fold changes were calculated using the $2^{-\Delta \Delta \mathrm{Ct}}$ method.

2.4.5. Western blot. IR HepG2 cells were incubated with PLP-1 $(30.8 \mu \mathrm{M})$ and Met $(2 \mathrm{mM})$ for $10 \mathrm{~h}$, and total protein was extracted using RIPA buffer containing PMSF (Solarbio, Beijing, China). Protein concentration was determined by BCA protein assay kit (Solarbio, Beijing, China) and proteins were separated by $7.5 \%$ SDS-PAGE and transferred to PVDF membranes (Millipore, USA). Non-specific bindings were blocked with a $5 \%$ nonfat milk solution for $2 \mathrm{~h}$ at room temperature, and target proteins were probed with primary antibodies against PI3K, AKT, GSK-3 $\beta$, FoxO1, PCK2 and G6Pase at $4{ }^{\circ} \mathrm{C}$ overnight. The blots were then incubated with the corresponding HRP-conjugated secondary antibody for $2 \mathrm{~h}$ at room temperature. The reactive protein was detected with an extreme hypersensitivity ECL chemiluminescence kit (Beyotime, Shanghai, China). The relative optical band densities were recorded by ImageJ software and were normalized to the $\beta$-actin chemiluminescence signal for relative total protein quantification.

2.4.6. Immunofluorescence staining for FoxO1. FoxO1 protein expression in HepG2 cells was determined by immunofluorescence assay as previously described. ${ }^{30,31}$ Firstly, HepG2 cells were cultured on glass coverslips and induced to insulin resistance as described above. After that, the cells were treated with PLP-1 (30.8 $\mu \mathrm{M})$ and Met $(2 \mathrm{mM})$ for $10 \mathrm{~h}$, and then washed with PBS three times, fixed in $2 \%(\mathrm{w} / \mathrm{v})$ paraformaldehyde for $15 \mathrm{~min}$ at room temperature, and then blocked with $10 \%$ blocking serum for $1 \mathrm{~h}$. Then, cells were incubated with FoxO1 antibody for $2 \mathrm{~h}$ at room temperature. After being washed 3 times, cells were incubated with Alexa Fluor 488-conjugated secondary antibody (Invitrogen, USA) for $1 \mathrm{~h}$ in darkness. The nuclei were stained with DAPI $(30 \mu \mathrm{L})$ for $15 \mathrm{~min}$. Fluorescent images were obtained with a positive fluorescence microscope (Eclipse Ni, Nikon, Japan). 


\subsection{Statistical analysis}

Each cell culture experiment was performed at least three separate times. All values were expressed as $(\bar{x} \pm s)$. The experimental data were statistically analyzed by ANOVA, where $P<0.05$ was assumed to be statistically significant. SPSS 19.0 software was used for statistical analysis.

\section{Results and discussion}

\subsection{Isolation and purification}

The crude polysaccharide (PLP) was obtained from the roots of $P$. lobata by the water-extraction and alcohol-precipitation method, and the yield was about $2.0 \%$. PLP was then separated by a DEAE-52 cellulose column to obtain water-eluted fraction. The fraction was further purified by a Sephadex G-200 column to obtain pure sub-fraction named PLP-1. The HPGPC trace showed a single symmetrical peak (Fig. 1), which indicated that PLP-1 was a homogeneous polysaccharide. The average molecular weight was $16.2 \mathrm{kDa}$ based on the equation of dextran standard curve $\left(\lg M_{\mathrm{W}}=-0.4232 t+9.5597, R^{2}=0.997\right)$.

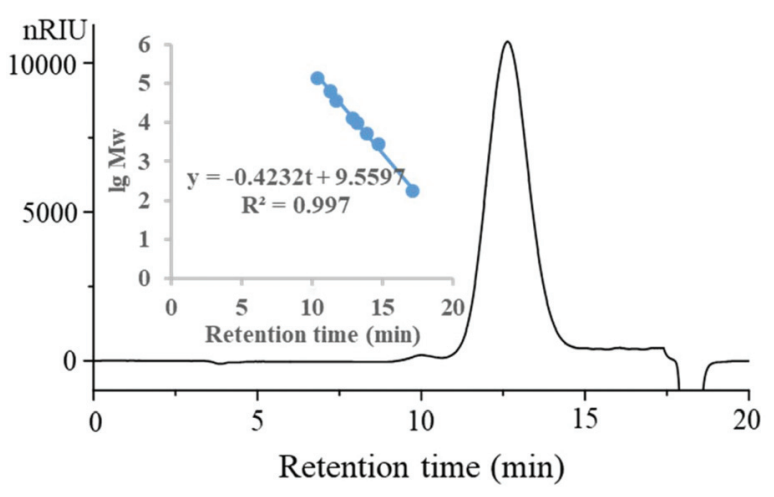

Fig. 1 HPGPC profile of PLP-1.
Moreover, the total sugar and protein contents of PLP-1 were determined to be $98.7 \%$ and $0.4 \%$, respectively (Table S2 $\dagger$ ).

\subsection{Monosaccharide composition and FT-IR spectrum}

PLP-1 was decomposed by acid hydrolysis, and its alditol acetates were subjected to GC-MS for analysis. Compared with monosaccharide standards, the results showed (Fig. 2A) that PLP-1 was composed of glucose as a glucan. Moreover, FT-IR spectral analysis is an effective method to study the structure of polysaccharides owing to the characteristic absorption of functional groups. As shown in Fig. 2B, a major broad peak at around $3305 \mathrm{~cm}^{-1}$ was due to $\mathrm{O}-\mathrm{H}$ stretching vibrations of hydroxyl group. The small band at $2923 \mathrm{~cm}^{-1}$ was attributed to the $\mathrm{C}-\mathrm{H}$ stretching and bending vibrations. The peak at $1642 \mathrm{~cm}^{-1}$ was caused by the bending vibration of $-\mathrm{OH}$. The absorption peak at $1361 \mathrm{~cm}^{-1}$ was attributed to variable angle vibrations of $\mathrm{C}-\mathrm{H} .{ }^{23,32}$ Furthermore, the absorption peaks at $1149 \mathrm{~cm}^{-1}, 1078 \mathrm{~cm}^{-1}$ and $1017 \mathrm{~cm}^{-1}$ were ascribed to the stretching vibrations of pyranose ring. ${ }^{33}$

\subsection{Methylation and NMR spectroscopy analysis}

Methylation analysis was applied to determine the linkage forms among monosaccharide units of PLP-1. Methylated alditol acetate (PMAA) derivatives were formed after PLP-1 being fully methylated, hydrolyzed and acetylated, followed by GC-MS measurement. It could be concluded that PLP-1 mainly contained two glycosidic linkages, namely $\rightarrow 3)$-D-Glcp- $(1 \rightarrow$ and $\rightarrow 4)$-D-Glcp-( $1 \rightarrow$, with a relative molar ratio of $7.0: 1.0$ (Table 1 ) based on analysis of PMAA peak retention time (Fig. S2†) and mass fragments described in the literature. ${ }^{34,35}$

The structure of PLP-1 was further determined by NMR spectra which are shown in Fig. 3. The chemical shift and coupling constant of the anomeric proton signals were used to determine the $\alpha / \beta$ configurations of residues. ${ }^{36,37}$ Two anomeric proton signals $\left(\delta_{\mathrm{H}} 5.30\right.$ and $\left.\delta_{\mathrm{H}} 4.55 \mathrm{ppm}\right)$ were identified in the ${ }^{1} \mathrm{H}$-NMR spectrum (Fig. 3A), which were ascribed to two
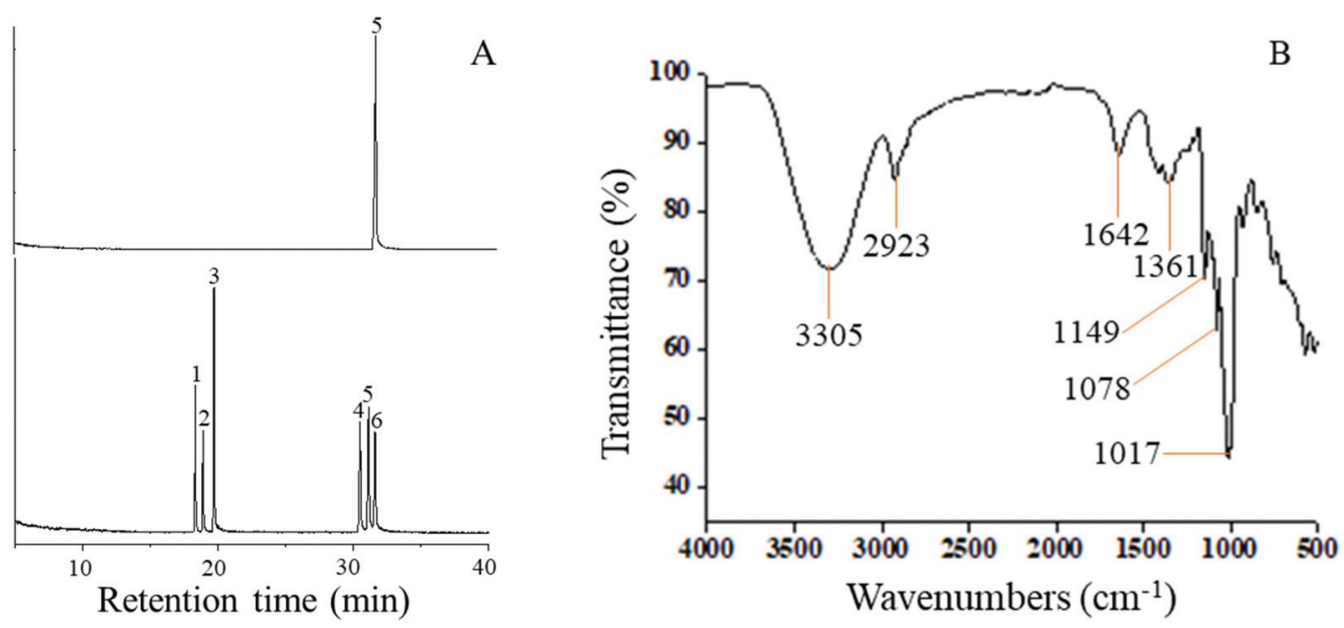

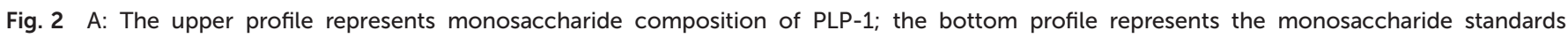

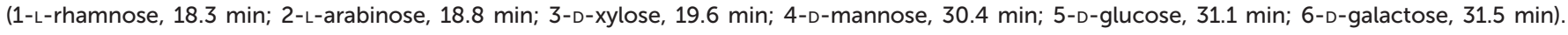
B: FT-IR spectrum of PLP-1. 
Table 1 The results of methylation analysis of PLP-1

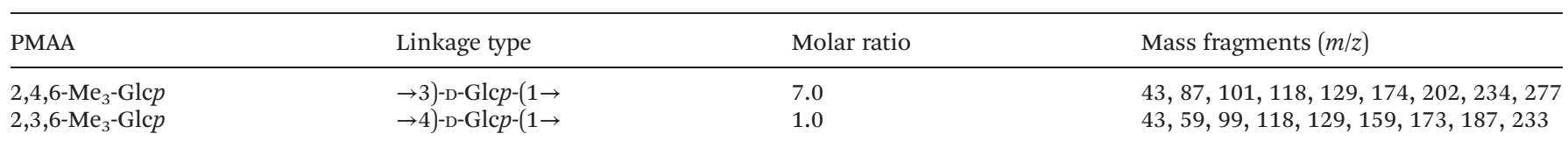

A

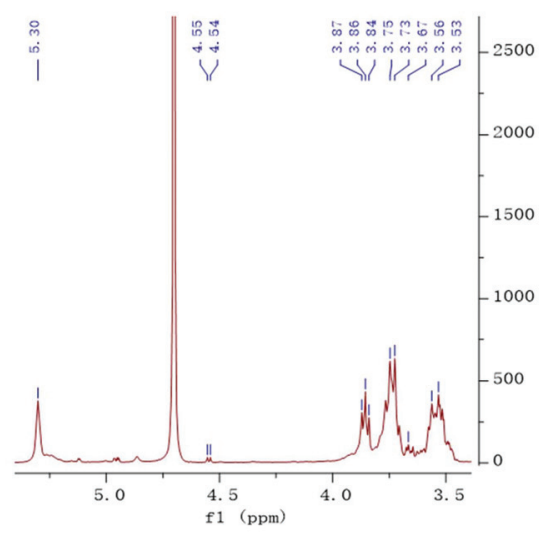

B
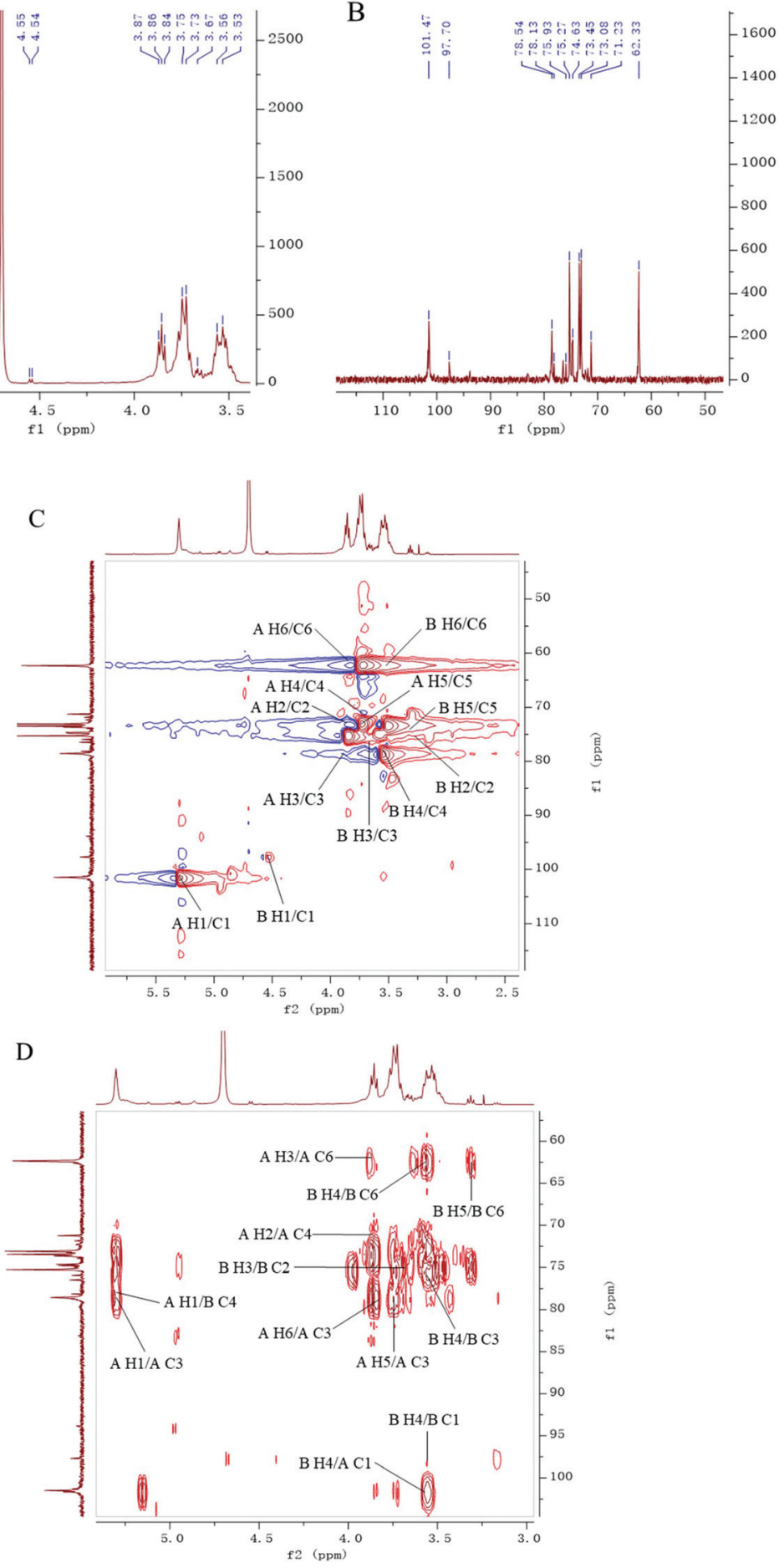

Fig. 3 NMR spectra of PLP-1: ${ }^{1} \mathrm{H}(\mathrm{A}) ;{ }^{13} \mathrm{C}(\mathrm{B})$; HSQC (C); HMBC (D). 
different residue types of residue $\mathrm{A}[\rightarrow 3)$-Glcp- $(1 \rightarrow]$ and residue $\mathrm{B}[\rightarrow 4)$-Glcp- $(1 \rightarrow]$ according to integration. $\delta_{\mathrm{H}} 5.30 \mathrm{ppm}(\mathrm{A} / \mathrm{H}-1)$ is inferred as $\alpha$-configuration owing to a small coupling constant $J=2.0 \mathrm{~Hz} . \quad \delta_{\mathrm{H}} 4.55 \mathrm{ppm}(\mathrm{B} / \mathrm{H}-1)$ is inferred as $\beta$-configuration due to a large coupling constant $J=8.0 \mathrm{~Hz}$. The two corresponding anomeric carbon signals $\delta_{\mathrm{C}} 101.5$ and $97.7 \mathrm{ppm}$ were determined in the ${ }^{13} \mathrm{C}-\mathrm{NMR}$ spectrum (Fig. 3B) by the correlations from $\delta_{\mathrm{H}} 5.30$ to $\delta_{\mathrm{C}} 101.5$ and $\delta_{\mathrm{H}} 4.55$ to $\delta_{\mathrm{C}}$ 97.7 on the basis of the HSQC spectrum (Fig. 3C).

In the $\mathrm{HMBC}$ spectrum (Fig. 3D), a cross-peak signal from $\delta_{\mathrm{H}} 5.30(\mathrm{~A} / \mathrm{H}-1)$ to $\delta_{\mathrm{C}} 78.6(\mathrm{~A} / \mathrm{C}-3)$ was assigned, which suggested a repeat unit $\rightarrow 3)-\alpha-D-G l c p(1 \rightarrow 3)-\alpha-D-G l c p(1 \rightarrow$ as backbone. In addition, the correlation between $\delta_{\mathrm{H}} 3.56$ $(\mathrm{B} / \mathrm{H}-4)$ and $\delta_{\mathrm{C}} 101.5(\mathrm{~A} / \mathrm{C}-1), \delta_{\mathrm{H}} 5.30(\mathrm{~A} / \mathrm{H}-1)$ and $\delta_{\mathrm{C}} 78.1$ (B/C-4) indicated that $\mathrm{C}-1$ of residue $\mathrm{A}$ was linked to $\mathrm{C}-4$ of residue B. Furthermore, in the DEPT- $135^{\circ}$ spectrum (Fig. S5 $\dagger$ ), PLP-1 had negative methylene signals at $\delta_{\mathrm{C}}$ $62.3 \mathrm{ppm}$ without downfield shift, indicating that there was an absence of linkage at C- 6 position of residues A and B, which were consistent with results of methylation. Thus, the possible structure of PLP-1 was deduced (Fig. S8 $\dagger$ ). Additionally, the signals for carbon and hydrogen for PLP-1 are fully shown in Table 2 according to the HMBC spectrum and the literature. ${ }^{36-40}$

Table $2{ }^{13} \mathrm{C}$ and ${ }^{1} \mathrm{H}$ NMR chemical shifts of PLP-1 recorded in $\mathrm{D}_{2} \mathrm{O}$

\begin{tabular}{|c|c|c|c|c|c|c|}
\hline \multirow[b]{2}{*}{ Sugar residue } & \multicolumn{6}{|c|}{ Chemical shift (ppm) } \\
\hline & $\mathrm{C} 1 / \mathrm{H} 1$ & $\mathrm{C} 2 / \mathrm{H} 2$ & $\mathrm{C} 3 / \mathrm{H} 3$ & $\mathrm{C} 4 / \mathrm{H} 4$ & C5/H5 & C6/H6 \\
\hline \multirow[t]{2}{*}{$\rightarrow 3)-\alpha-\mathrm{D}-\mathrm{Glc} p(1 \rightarrow(\mathrm{A})$} & 101.5 & 73.1 & 78.5 & 71.2 & 73.5 & 62.3 \\
\hline & 5.30 & 3.86 & 3.87 & 3.73 & 3.75 & $3.84 / 3.52$ \\
\hline \multirow[t]{2}{*}{$\rightarrow 4)-\beta-\mathrm{D}-\mathrm{Glc} p(1 \rightarrow(\mathrm{B})$} & 97.7 & 75.3 & 75.9 & 78.1 & 74.6 & 62.3 \\
\hline & 4.55 & 3.24 & 3.67 & 3.56 & 3.31 & $3.82 / 3.53$ \\
\hline
\end{tabular}
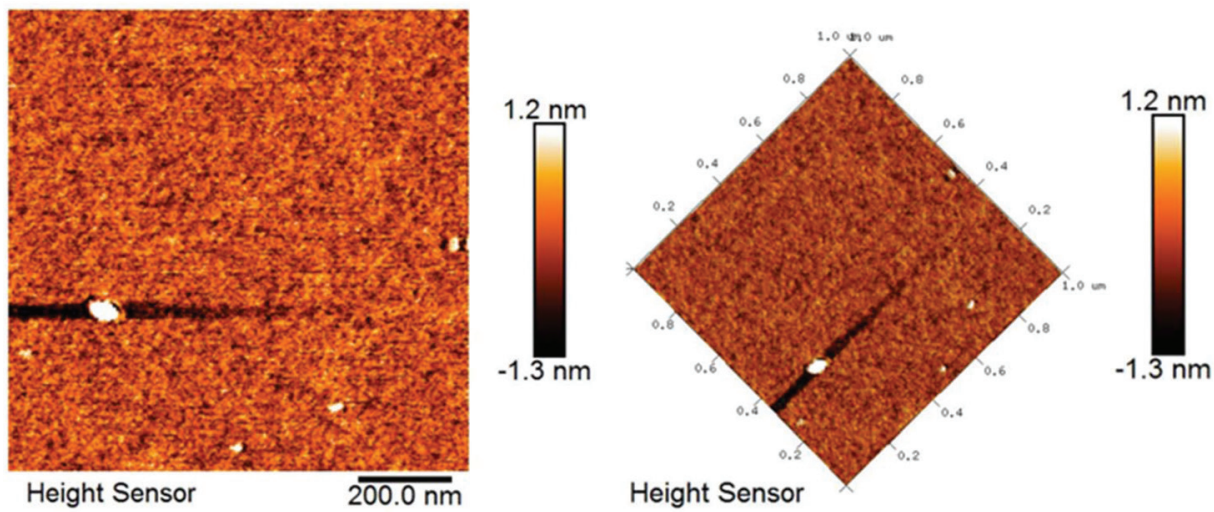

Fig. 4 AFM images of PLP-1.
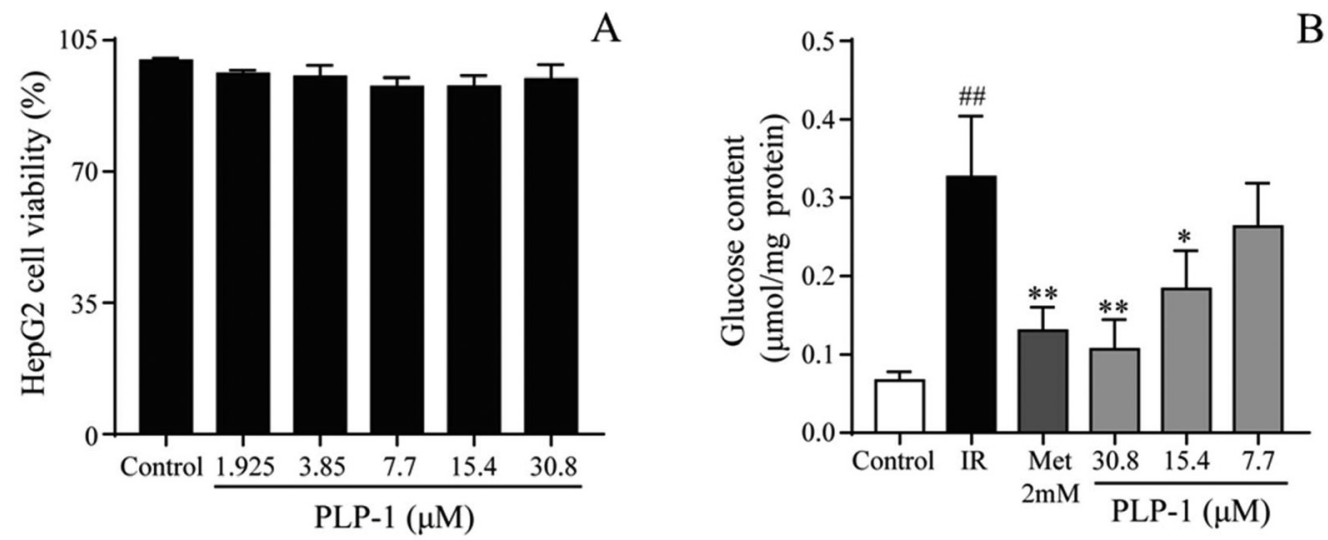

Fig. 5 The viability of HepG2 cells treated with PLP-1 (A). The glucose content of PLP-1 in IR cells (B). Values are the mean \pm SD; $\# \#<<0.01$ vs. the normal control group; ${ }^{*} p<0.05,{ }^{* *} p<0.01$ vs. the model group. 


\subsection{AFM analysis}

AFM is a powerful technique to characterize the microstructure of polysaccharides. ${ }^{39,41}$ Therefore, AFM was utilized to observe the molecular morphology of PLP-1. As shown in Fig. 4, the 2D images demonstrated that the polysaccharide rings of PLP-1 were closely arranged due to intermolecular van der Waals forces, and the polysaccharide chains were also closely twisted together to form a structure of equally distributed clusters. The surface roughness of PLP-1 ranged from approximately -1.3 to $1.2 \mathrm{~nm}$.

\subsection{Effect of PLP-1 on glucose content in the IR cell models}

When cells were treated with $0.5 \mathrm{mM}$ PA and $30 \mathrm{mM}$ Glu for $8 \mathrm{~h}$, the glucose content was increased significantly compared with the normal group $(P<0.01)$, indicating that establishment of insulin resistance model was due to the accumulation of PA. MTT assay results of PLP-1 (Fig. 5A) showed that there was no cytotoxicity at a concentration of $1.925-30.8 \mu \mathrm{M}$. To assess the effect of PLP-1 on reversing insulin resistance, the IR cells were incubated with PLP-1 (30.8 $\mu \mathrm{M})$. In Fig. 5B, compared with model group, PLP-1 obviously improved
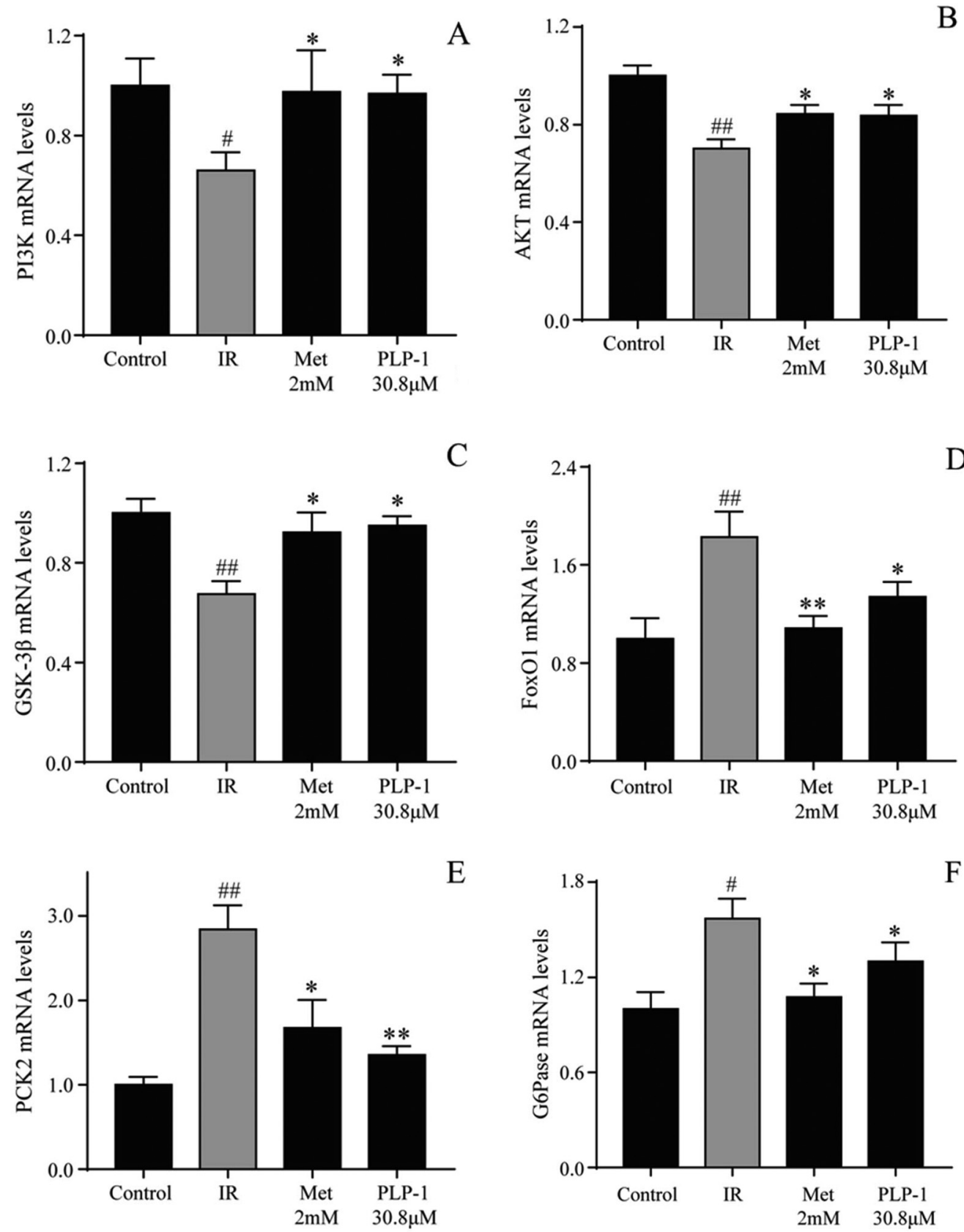

E

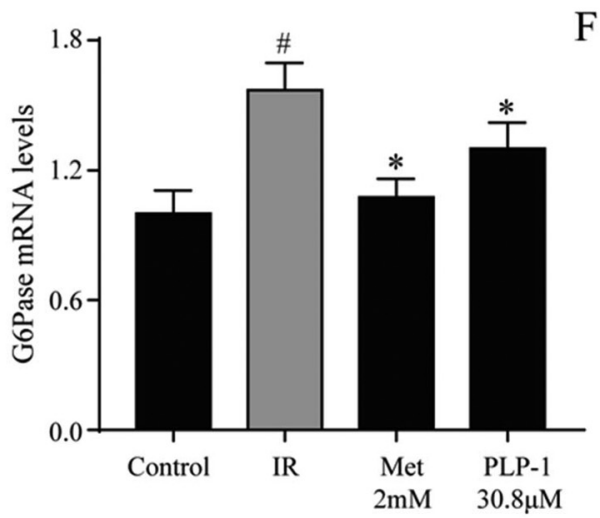

Fig. 6 The effect of PLP-1 on mRNA expression in IR HepG2 cells (A: PI3K; B: AKT; C: GSK-3ß; D: FoxO1; E: PCK2; F: G6Pase). Values are the mean \pm SD; ${ }^{*} p<0.05,{ }^{\# \#} p<0.01$ vs. the normal control group; ${ }^{*} p<0.05,{ }^{* *} p<0.01$ vs. the model group. 
glucose content in the IR HepG2 cells. At a concentration of $30.8 \mu \mathrm{M}$, PLP-1 showed an obvious glucose content decrease which was nearly comparable to the normal group. Therefore, PLP-1 (30.8 $\mu \mathrm{M})$ was chosen for the following mechanism study.
3.6. PLP-1 activated the PI3K/AKT signal pathway in IR HepG2 cells

It is generally acknowledged that the PI3K/AKT signaling pathway plays a crucial role in the regulation of glucose metabolism, including glucose transport, glycogen synthesis and
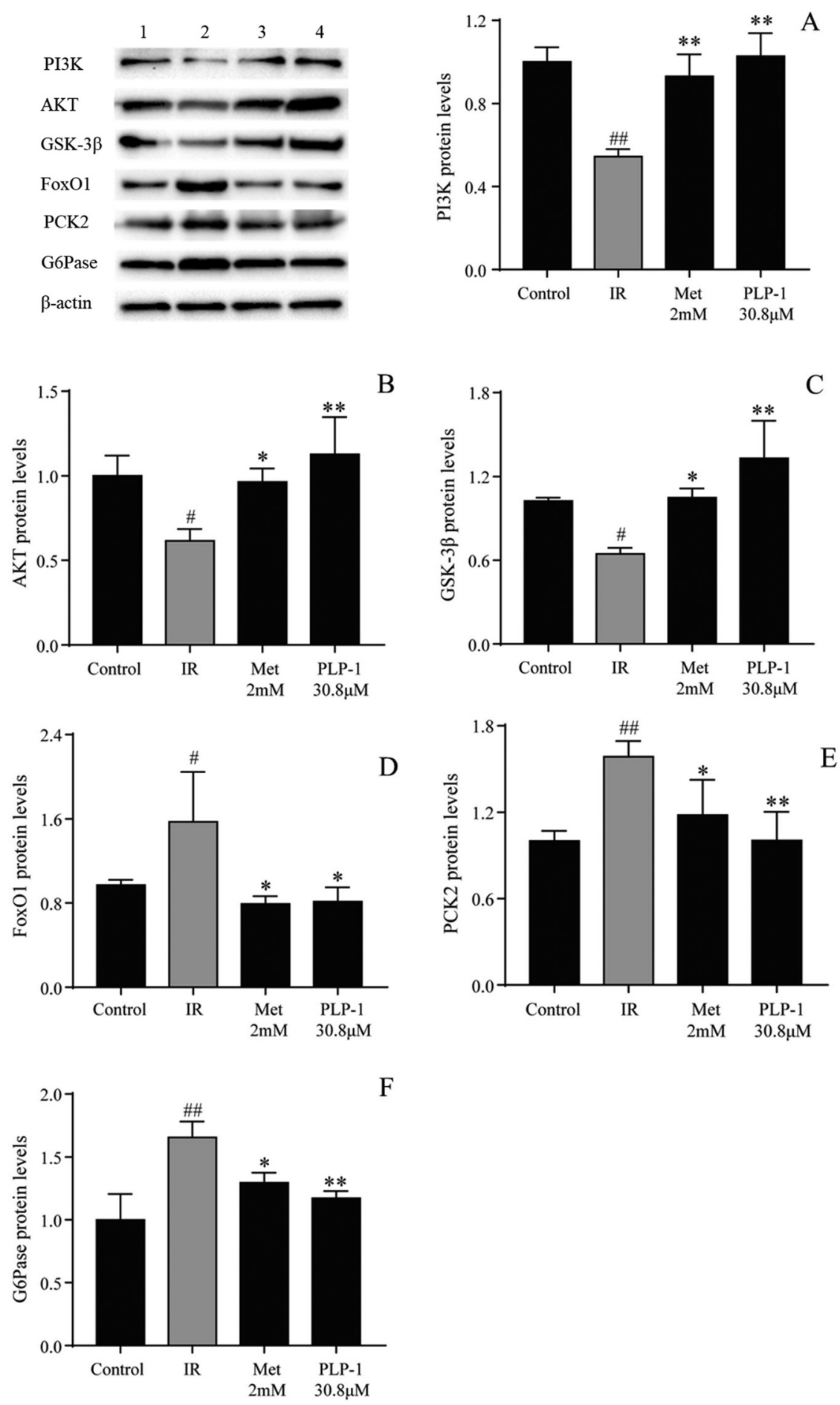

Fig. 7 The effect of PLP-1 on the protein expression in IR HepG2 cells (A: PI3K; B: AKT; C: GSK-3B; D: FoxO1; E: PCK2; F: G6Pase) (1: control; 2: model; 3: Met; 4: PLP-1). Values are the mean \pm SD; ${ }^{\#} p<0.05,{ }^{\# \#} p<0.01$ vs. the normal control group; ${ }^{*} p<0.05,{ }^{\star *} p<0.01$ vs. the model group. 


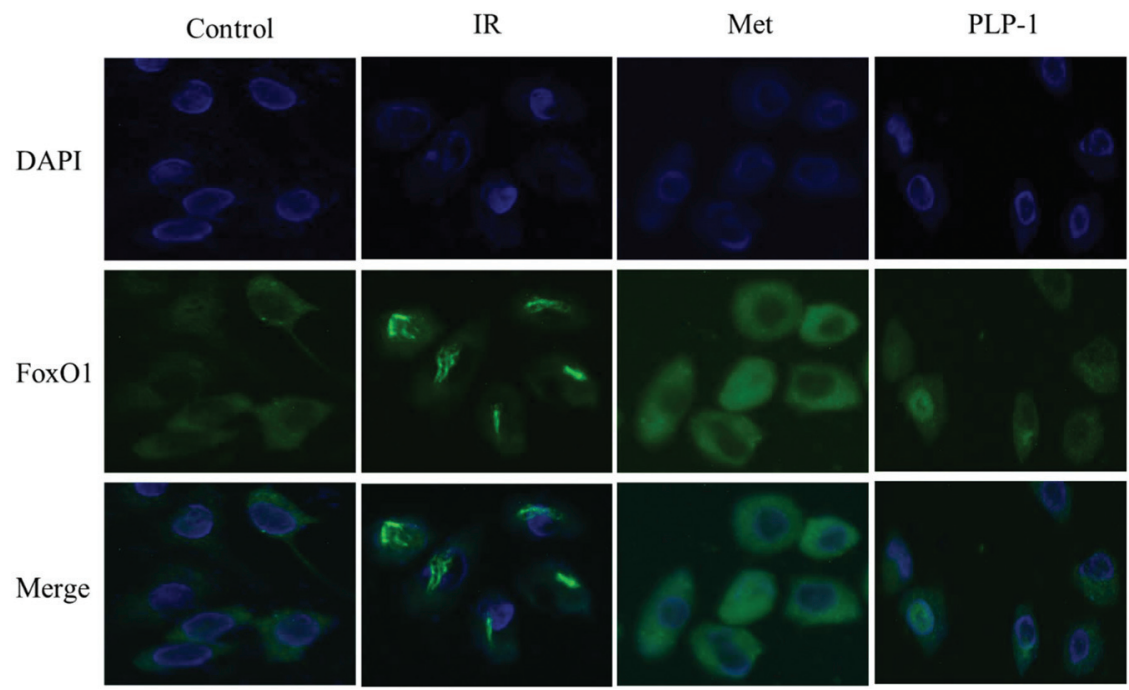

Fig. 8 PLP-1 enhanced FoxO1 protein expression in IR HepG2 cells (control: normal group; IR: model group; Met: 2 mM; PLP-1: $30.8 \mu$ M).

gluconeogenesis suppression. ${ }^{42}$ PI3K is considered as a second messenger, playing an important role in cellular chemical signal transfer. Activated PI3K can phosphorylate AKT, thus activating AKT. ${ }^{43}$ GSK- $3 \beta$ is a negative regulatory gene in glycogen synthesis, which is regulated by AKT. In the state of insulin resistance, AKT phosphorylation is weakened, the activity of GSK-3 $\beta$ is strong, which inhibits the activity of glycogen synthase, thus inhibiting glycogen synthesis. On the contrary, activated AKT can reduce the expression of GSK-3 $\beta$ and promote glycogen synthesis. ${ }^{44,45}$ Besides, AKT stimulation can restrain gluconeogenesis by inhibiting PCK2 and G6Pase expressions and phosphorylating FoxO1. ${ }^{46}$ Therefore, the PI3K/AKT signaling pathway plays an exceedingly significant role in mediating insulin metabolism and is closely correlated with insulin resistance.

In recent years, IR HepG2 cell models have been used to study the hypoglycemic activities and mechanisms of plant polysaccharides. For instance, the polysaccharide EFSP-1 from Euryale ferox increased the expression of IRS-1, PI3K, AKT and GLUT4 in mRNA and protein levels in IR HepG2 cells. ${ }^{32}$ In addition, previous research reported that polysaccharides LSP, OJP and LMP from herbs Maidong upregulated the levels of PI3K, AKT, InsR, and PPAR $\gamma$ and downregulated the levels of PTP1B in mRNA and protein expression in IR HepG2 cells. ${ }^{23}$

To determine whether the PI3K/AKT signal pathway was affected by PLP-1 treatment in IR HepG2 cells, the expressions of main protein and mRNA in glucose transport pathway including PI3K, AKT, GSK-3 $\beta$, FoxO1, PCK2 and G6Pase were investigated. As shown in Fig. 6, the downregulation of mRNA expression of PI3K, AKT, and GSK-3 $\beta$ was observed in the model group, while the upregulation of mRNA expression of FoxO1, PCK2 and G6Pase was observed in the model group, indicating that there was insulin resistance in HepG2 cells. When treated with PLP-1 and Met, both groups obviously increased the expression of PI3K, AKT, and GSK-3 $\beta$ and decreased the expression of FoxO1, PCK2, and G6Pase in
mRNA levels as compared to the model group. Meanwhile, both groups also significantly increased the expression of PI3K, AKT, and GSK-3 $\beta$ and decreased the expression of FoxO1, PCK2, and G6Pase in protein levels as compared to the IR control (Fig. 7). Furthermore, to confirm the role of FoxO1 in gluconeogenesis stimulated by PLP-1 and Met, the expression of FoxO1 was demonstrated by immunofluorescence staining. As shown in Fig. 8, PLP-1 and Met obviously increased FoxO1 expression and enhanced nuclear-cytoplasmic translocation in HepG2 cells compared with the model group. These results indicated that IR HepG2 cells could be mitigated by treatment with PLP-1, the mechanism of which may be associated with the regulation of PI3K/AKT/FoxO1 signaling pathway to reduce the content of glucose.

\section{Conclusions}

In this study, a novel water-soluble polysaccharide, PLP-1, was purified from the roots of $P$. lobata. PLP-1 is a glucan with a molecular weight of $16.2 \mathrm{kDa}$. The backbone of PLP-1 was mainly composed of $\rightarrow 3)-\alpha-\mathrm{D}-\mathrm{Gl} c p-(1 \rightarrow$ and $\rightarrow 4)-\beta$-D-Glc $p-(1 \rightarrow$ with a relative ratio of $7.0: 1.0$ and special spatial structure. PLP-1 could ameliorate adverse effects of glucose metabolism caused by $\mathrm{PA}$ and high glucose via down-regulating the expression of FoxO1, which might occur by activating the PI3K/ AKT/FoxO1 signal pathway in IR HepG2 cells. These findings provide evidence that PLP-1 may serve as an alternative functional food or clinical adjuvant therapy to mitigate metabolic disorders with T2DM. However, the hypoglycemic effect and underlying mechanisms of PLP-1 require further verification in vivo.

\section{Funding}

This work was supported by the National Natural Science Foundations of China under grant number 81860684 
and the National Key R\&D Program of China (numbers 2019YFC1712300 and 2017YFC1702902).

\section{Conflicts of interest}

No potential conflict of interest was reported by the authors.

\section{References}

1 K. Ogurtsova, J. D. da Rocha Fernandes, Y. Huang, U. Linnenkamp, L. Guariguata, N. H. Cho, D. Cavan, J. E. Shaw and L. E. Makaroff, IDF Diabetes Atlas: Global estimates for the prevalence of diabetes for 2015 and 2040, Diabetes Res. Clin. Pract., 2017, 128, 40-50.

2 L. M. Jaacks, K. R. Siegel, U. P. Gujral and K. M. V. Narayan, Type 2 diabetes: A 21st century epidemic, Best Pract. Res., Clin. Gastroenterol., 2016, 30, 331-343.

3 W. Kerner and J. Brückel, Definition, classification and diagnosis of diabetes mellitus, Exp. Clin. Endocrinol. Diabetes, 2014, 122, 384-386.

4 K. P. Wang, Z. H. Tang, Z. M. Zheng, P. Cao, W. Z. Shui, Q. Li and Y. Zhang, Protective effects of Angelica sinensis polysaccharide against hyperglycemia and liver injury in multiple low-dose streptozotocin-induced type 2 diabetic BALB/c mice, Food Funct., 2016, 7, 4889-4897.

5 C. Chen, Q. Huang, C. Li and X. Fu, Hypoglycemic effects of a Fructus Mori polysaccharide in vitro and in vivo, Food Funct., 2017, 8, 2523-2535.

6 M. I. Kazeem and T. C. Davies, Anti-diabetic functional foods as sources of insulin secreting, insulin sensitizing and insulin mimetic agents, J. Funct. Foods, 2016, 20, 122138.

7 J. Martel, D. M. Ojcius, C. J. Chang, C.-S. Lin, C. C. Lu, Y. F. Ko, S. F. Tseng, H. C. Lai and J. D. Young, Anti-obesogenic and antidiabetic effects of plants and mushrooms, Nat. Rev. Endocrinol., 2017, 13, 149.

8 K. H. Wong, G. Q. Li, K. M. Li, V. Razmovski-Naumovski and K. Chan, Optimisation of Pueraria isoflavonoids by response surface methodology using ultrasonic-assisted extraction, Food Chem., 2017, 231, 231-237.

9 J. K. Prasain, N. Peng, R. Rajbhandari and J. M. Wyss, The Chinese Pueraria root extract (Pueraria lobata) ameliorates impaired glucose and lipid metabolism in obese mice, Phytomedicine, 2012, 20, 17-23.

10 C. F. Ng, C. M. Koon, D. W. S. Cheung, M. Y. Lam, P. C. Leung, C. B. S. Lau and K. P. Fung, The anti-hypertensive effect of Danshen (Salvia miltiorrhiza) and Gegen (Pueraria lobata) formula in rats and its underlying mechanisms of vasorelaxation, J. Ethnopharmacol., 2011, 137, 1366-1372.

11 L. Bebrevska, K. Foubert, N. Hermans, S. Chatterjee, E. Van Marck, G. De Meyer, A. Vlietinck, L. Pieters and S. Apers, In vivo antioxidative activity of a quantified Pueraria lobata root extract, J. Ethnopharmacol., 2010, 127, 112-117.
12 T. Tanaka, H. Tang, F. Yu, S. Michihara, Y. Uzawa, N. Zaima, T. Moriyama and Y. Kawamura, Kudzu (Pueraria lobata) vine ethanol extracts improve ovariectomy-induced bone loss in female mice, J. Agric. Food Chem., 2011, 59, 13230-13237.

13 Z. Dong, M. Zhang, H. Li, Q. Zhan, F. Lai and H. Wu, Structural characterization and immunomodulatory activity of a novel polysaccharide from Pueraria lobata (Willd.) Ohwi root, Int. J. Biol. Macromol., 2020, 154, 1556-1564.

14 Y. Yu, M. Y. Shen, Q. Q. Song and J. H. Xie, Biological activities and pharmaceutical applications of polysaccharide from natural resources: A review, Carbohydr. Polym., 2018, 183, 91-101.

15 C. C. Cai, X. U. Yan-Ying, H. X. Wang, S. Wang and D. O. Endocrinology, The study of therapeutic effect and mechanism of Puerariae Radix polysaccharides on type 2 diabetes mellitus rats, Tianjin J. Tradit. Chin. Med., 2014, 94-97, DOI: 10.11656/j.issn.1672-1519.2014.02.09.

16 J. J. Wen, H. Gao, J. L. Hu, Q. X. Nie, H. H. Chen, T. Xiong, S. P. Nie and M. Y. Xie, Polysaccharides from fermented Momordica charantia ameliorate obesity in high-fat induced obese rats, Food Funct., 2019, 10, 448-457.

17 X. H. Yu, Y. Liu, X. L. Wu, L. Z. Liu and D. D. Song, Isolation, purification, characterization and immunostimulatory activity of polysaccharides derived from American ginseng, Carbohydr. Polym., 2016, 156, 9-18.

18 Q. X. Yuan, L. Y. Zhao, Q. Q. Cha, Y. Sun, H. Ye and X. X. Zeng, Structural Characterization and Immunostimulatory Activity of a Homogeneous Polysaccharide From Sinonovacula Constricta, J. Agric. Food Chem., 2015, 63, 7986-7994.

19 M. A. M. Ghoneim, A. I. Hassan, M. G. Mahmoud and M. S. Asker, Effect of polysaccharide from Bacillus subtilis sp. on cardiovascular diseases and atherogenic indices in diabetic rats, BMC Complementary Altern. Med., 2016, 16, 112.

20 N. Blumenkrantz and A. H. Gustav, New method for quantitative determination of uronic acids, Anal. Chem., 1973, 54, 484-489.

21 M. M. Bradford, A rapid and sensitive method for the quantitation of microgram quantities of protein utilizing the principle of protein-dye binding, Anal. Biochem., 1976, 72, 248-254.

22 J. Lehrfeld, Simultaneous gas-liquid chromatographic determination of aldonic acids and aldoses, Anal. Chem., 1985, 57, 346-348.

23 Y. J. Gong, J. Zhang, F. Gao, J. W. Zhou, Z. N. Xiang, C. G. Zhou, L. S. Wan and J. C. Chen, Structure features and in vitro hypoglycemic activities of polysaccharides from different species of Maidong, Carbohydr. Polym., 2017, 173, 215-222.

24 I. M. Sims, S. M. Carnachan, T. J. Bell and S. F. R. Hinkley, Methylation analysis of polysaccharides: Technical advice, Carbohydr. Polym., 2018, 188, 1-7.

25 C. L. Cao, C. Li, Q. Chen, Q. Huang, M. E. M. Pérez and X. Fu, Physicochemical characterization, potential anti- 
oxidant and hypoglycemic activity of polysaccharide from Sargassum pallidum, Int. J. Biol. Macromol., 2019, 139, 1009-1017.

26 Y. Yao, Y. Y. Zhu, Y. Gao, Z. X. Shi, Y. B. Hu and G. X. Ren, Suppressive effects of saponin-enriched extracts from quinoa on 3 T3-L1 adipocyte differentiation, Food Funct., 2015, 6, 3282-3290.

27 F. J. Yan, G. H. Dai and X. D. Zheng, Mulberry anthocyanin extract ameliorates insulin resistance by regulating PI3K/ AKT pathway in HepG2 cells and $\mathrm{db} / \mathrm{db}$ mice, J. Nutr. Biochem., 2016, 36, 68-80.

28 Q. Zhang, X. J. Kong, H. Yuan, H. J. Guan, Y. Li and Y. C. Niu, Mangiferin Improved Palmitate-Induced-Insulin Resistance by Promoting Free Fatty Acid Metabolism in HepG2 and C2C12 Cells via PPAR $\alpha$ : Mangiferin Improved Insulin Resistance, J. Diabetes Res., 2019, 2019, 2052675.

29 M. Nácher-Vázquez, N. Ballesteros, Á. Canales, S. Rodríguez Saint-Jean, S. I. Pérez-Prieto, A. Prieto, R. Aznar and P. López, Dextrans produced by lactic acid bacteria exhibit antiviral and immunomodulatory activity against salmonid viruses, Carbohydr. Polym., 2015, 124, 292-301.

30 L. H. Chen, X. H. Sun, H. M. Xiao, F. T. Xu, Y. Yang, Z. Y. Lin, Z. Q. Chen, S. J. Quan and H. Q. Huang, PAQR3 regulates phosphorylation of FoxO1 in insulin-resistant HepG2 cells via NF-кB signaling pathway, Exp. Cell Res., 2019, 381, 301-310.

31 H. Matsuzaki, H. Daitoku, M. Hatta, K. Tanaka and A. Fukamizu, Insulin-induced phosphorylation of FKHR (Foxo1) targets to proteasomal degradation, Proc. Natl. Acad. Sci. U. S. A., 2003, 100, 11285-11290.

32 W. N. Zhang, R. N. Su, L. L. Gong, W. W. Yang, J. Chen, R. Yang, Y. Wang, W. J. Pan, Y. M. Lu and Y. Chen, Structural characterization and in vitro hypoglycemic activity of a glucan from Euryale ferox Salisb. seeds, Carbohydr. Polym., 2019, 209, 363-371.

33 Y. F. Gao, Y. B. Zhou, Q. Zhang, K. Zhang, P. Peng, L. Chen and B. Xiao, Hydrothermal extraction, structural characterization, and inhibition HeLa cells proliferation of functional polysaccharides from Chinese tea Zhongcha 108, J. Funct. Foods, 2017, 39, 1-8.

34 J. Y. Jiang, F. S. Kong, N. S. Li, D. Z. Zhang, C. Y. Yan and H. C. Lv, Purification, structural characterization and in vitro antioxidant activity of a novel polysaccharide from Boshuzhi, Carbohydr. Polym., 2016, 147, 365-371.

35 C. Xu, N. B. Qin, C. Y. Yan and S. M. Wang, Isolation, purification, characterization and bioactivities of a glucan from the root of Pueraria lobata, Food Funct., 2018, 9, 2644-2652.
36 E. I. Nep, S. M. Carnachan, N. C. Ngwuluka, V. Kontogiorgos, G. A. Morris, I. M. Sims and A. M. Smith, Structural characterisation and rheological properties of a polysaccharide from sesame leaves (Sesamum radiatum Schumach. \& Thonn.), Carbohydr. Polym., 2016, 152, 541547.

37 K. J. Murphy, N. McLay and D. A. Pye, Structural Studies of Heparan Sulfate Hexasaccharides: New Insights into Iduronate Conformational Behavior, J. Am. Chem. Soc., 2008, 130, 12435-12444.

38 X. M. Wang, R. G. Sun, J. Zhang, Y. Y. Chen and N. N. Liu, Structure and antioxidant activity of polysaccharide POJ-U1a extracted by ultrasound from Ophiopogon japonicus, Fitoterapia, 2012, 83, 1576-1584.

39 J. K. Yan, Y. Y. Wang, Z. B. Wang, H. L. Ma, J. J. Pei and J. Y. Wu, Structure and antioxidative property of a polysaccharide from an ammonium oxalate extract of Phellinus linteus, Int. J. Biol. Macromol., 2016, 91, 92-99.

40 T. Zhao, G. H. Mao, W. W. Feng, R. W. Mao, X. Y. Gu, T. Li, Q. Li, Y. T. Bao, L. Q. Yang and X. Y. Wu, Isolation, characterization and antioxidant activity of polysaccharide from Schisandra sphenanthera, Carbohydr. Polym., 2014, 105, 2633.

41 N. B. Liao, S. G. Chen, X. Q. Ye, J. J. Zhong, X. Ye, X. Z. Yin, J. Tian and D. H. Liu, Structural characterization of a novel glucan from Achatina fulica and its antioxidant activity, J. Agric. Food Chem., 2014, 62, 2344-2352.

42 E. L. Whiteman, H. Cho and M. J. Birnbaum, Role of Akt/ protein kinase B in metabolism, Trends Endocrinol. Metab., 2002, 13, 444-451.

43 X. T. Feng, T. Z. Wang, J. Leng, Y. Chen, J. B. Liu, Y. Liu and W. J. Wang, Palmitate Contributes to Insulin Resistance through Downregulation of the Src-Mediated Phosphorylation of Akt in C2C12 Myotubes, Biosci., Biotechnol., Biochem., 2012, 76, 1356-1361.

44 M. Wan, K. F. Leavens, R. W. Hunter, S. Koren, A. von Wilamowitz-Moellendorff, M. Lu, S. Satapati, Q. Chu, K. Sakamoto, S. C. Burgess and M. J. Birnbaum, A noncanonical, GSK3-independent pathway controls postprandial hepatic glycogen deposition, Cell Metab., 2013, 18, 99-105.

45 C. Lipina, X. Huang, D. Finlay, E. J. McManus, D. R. Alessi and C. Sutherland, Analysis of hepatic gene transcription in mice expressing insulin-insensitive GSK3, Biochem. J., 2005, 392, 633-639.

46 P. J. Klover and R. A. Mooney, Hepatocytes: critical for glucose homeostasis, Int. J. Biochem. Cell Biol., 2004, 36, 753-758. 